\title{
THE ROLE OF THE GLOBULAR AMPHORA CULTURE IN THE DEVELOPMENT OF THE UPPER NEMAN COMMUNITIES
}

(C) 2019

\author{
Vaitovich Aliaksandra Uladzimirauna, candidate of historical sciences, \\ associate professor of the Department of Archaeology and Special Historical Disciplines \\ Belarusian State University (Minsk, Republic of Belarus)
}

\begin{abstract}
The paper discusses the problems of the Globular Amphora Culture (hereinafter the GAC) in the Upper Neman region. According to the proposition of M. Shmyt the sources related to the GAC have been divided in two groups. The first group is made up of the so-called pure sources i.e. the materials directly related to the GAC although hypothetically at times. It includes cemeteries, flint mines and workshops as well as finds of the quadrangular ground flint axes and chisels. The second group comprises so-called syncretic sources associated with the broad understood GAC traditions. The traits genetically linked to the GAC could be identified in materials of the Neman Culture as well as the local groups of the Corded Ware culture's Range. The presence of the GAC people and traditions in the area in question is dated to the second quarter III - first quarter II BC. Two main forms of transfer the GAC traditions have been distinguished. Firstly, the Upper Neman region was the territory of the direct contacts between the GAC people and the local populations. Secondly, the GAC elements had been distributed in the synthesized forms. The major source of the synthesized GAC traits was the Rzucewo Culture as well as the Middle Dnieper Culture. The prospects of the archaeological research are discussed. On the current stage of the research, the issue of the chronology of the GAC traditions spreading in the area in question requires a more detailed study. Top priority should also be given to a thorough investigation of the GAC role in the socio-economic transformation of the Upper Neman population in the III - the beginning II mill. BC.

Keywords: Globular Amphora Culture; Neman Culture; Corded Ware culture's Range; graves; flint mines; ceramics; ornamentation; flint axes and chisels; cultural traits; traditions; cultural processes; borrowings; farming; Late Neolithic; Republic of Belarus; Upper Neman region.
\end{abstract}

УДК 902. 903. 023

DOI 10.24411/2309-4370-2019-12205

Статья поступила в редакцию 28.01.2019

\section{О ТЕХНОЛОГИИ ИЗГОТОВЛЕНИЯ КЕРАМИКИ ИЗ ЭНЕОЛИТИЧЕСКИХ СЛОЕВ ПОСЕЛЕНИЯ РАКУШЕЧНЫЙ ЯР}

(C) 2019

Васильева Ирина Николаевна, кандидат исторических наук, старший научный сотрудник научно-исследовательской части Самарский государственный сочиально-педагогический университет (2. Самара, Российская Федераџия)

Аннотация. В работе представлены итоги технико-технологического анализа керамики из энеолитических слоев поселения Ракушечный Яр, расположенного на о. Поречный (р. Дон, Ростовская обл., Российская Федерация). Методологической основой проведенного исследования является историко-культурный подход к изучению древней керамики, разработанный в российской археологии А.А. Бобринским. Методы: бинокулярная микроскопия, трасология и эксперимент (физическое моделирование). Микроскопическому изучению был подвергнут 141 образец керамики (условно отдельных сосудов) из слоев №№ 5-2 Ракушечного Яра. Полученная технологическая информация позволила реконструировать приемы и способы изготовления энеолитической посуды на всех ступенях производства в рамках подготовительной, созидательной и закрепительной стадий гончарной технологии. Базируясь на этих данных, в статье дана общая характеристика энеолитического гончарства. Был осуществлен сравнительный анализ гончарной технологии неолитического и энеолитического населения, обитавшего на стоянке Ракушечный Яр. По его итогам выделены черты сходства и различия энеолитических и неолитических гончарных традиций. Особое внимание уделено вопросу о возможных истоках новых традиций, получивших распространение в период энеолита. К ним относятся традиции отбора илистых глин, введения в формовочные массы искусственных добавок: дробленой раковины, пуха птиц, песка.

Ключевые слова: Нижнее Подонье; поселение Ракушечный Яр; неолит; энеолит; керамика; историкокультурный подход к изучению керамики; бинокулярная микроскопия; трасология; эксперимент; гончарная технология; культурные традиции; сравнительный анализ энеолитических и неолитических гончарных традиций.

Введение

Суть многих проблем современной археологии (в том числе - выделения культурных областей, горизонтов, типов эпохи неолита, археологических культур энеолитического периода, а также обоснования перехода от неолита к энеолиту) зачастую сводится к аргументированному извлечению информации из имеющихся археологических источников и доказательной интерпретации полученных данных, т.е. к выбору методики. Среди российских археологов общепринятым является мнение, что наиболее массовым и информативным источником в реконструкции 
культурно-исторических процессов в неолите - энеолите является керамика [1-3]. В настоящее время довольно широко применяется историко-культурный подход к изучению керамики, разработанный А.А. Бобринским [4-6]. В рамках данного исследовательского подхода существуют методики исследования форм сосудов [7]; орнамента [8; 9]; технологии их изготовления [4; 6], а также предложена структура научного исследования керамики с использованием метода физического моделирования [10; 11]. При изучении гончарной технологии основное внимание уделяется выявлению конкретных навыков труда гончаров, применявшихся в изготовлении анализируемой посуды. Методика выделения информации о приемах труда по археологической керамике базируется на бинокулярной микроскопии, трасологии и эксперименте.

В рамках историко-культурного подхода была проанализирована неолитическая керамика поселения Ракушечный Яр, расположенного на острове Поречный (р. Дон, недалеко от ст. Раздорская Ростовской области Российской Федерации). Результаты изучения подробно опубликованы [12-14]. При обобщении итогов раскопок памятника в 1969 1979 гг. Т.Д. Белановская предложила объединить небольшие по мощности горизонты №№ 23-6 в один неолитический культурный слой, который был сформирован на раннем этапе бытования стоянки $[15$, c. 13]; слои 4-2 были датированы энеолитом, а слой 1 - эпохой бронзы [15, с. 27]; позднее материалы энеолитического времени (слои 5-2) были отнесены Н.С. Котовой к нижнедонской культуре [16, c. 28]. В последние годы раскопки поселения Ракушечный Яр были возобновлены экспедицией под руководством А.В. и В.В. Цыбриев. В 2018 г. автору удалось проанализировать керамику из верхних слоев их раскопа (выражаю искреннюю благодарность исследователям за разрешение ознакомиться с новым материалом). Накопленная база источников позволяет дать более полную характеристику энеолитической гончарной технологии и обратиться к сравнительному анализу данных по гончарной технологии неолита и энеолита. Таким образом, задачами данной статьи являются: введение в научный оборот итогов технико-технологического анализа керамики из энеолитических слоев поселения Ракушечный Яр (№№ 5-2) и сравнение гончарной технологии неолитического и энеолитического населения стоянки с целью выявления их сходства и различий, наличия черт преемственности, а также гомогенности энеолитических коллективов.

\section{Основная часть}

База источников включает данные технико-технологического анализа 352 образцов керамики (условно отдельных сосудов): 211 - из неолитических и 141 - из энеолитических слоев стоянки Ракушечный Яр. Как уже говорилось, результаты изучения керамики эпохи неолита этого памятника опубликованы [1214]. В данной статье рассматриваются результаты исследования керамики периода энеолита. Соотнесение горизонтов и слоев раскопа Т.Д. Белановской и раскопа А.В. и В.В. Цыбриев было произведено авторами последних раскопок, и в данной работе используется их идентификация.
Полученные данные о приемах изготовления энеолитической керамики поселения Ракушечный Яр излагаются в соответствии со структурой гончарного производства, которая состоит из 10 ступеней в рамках 3 стадий (подготовительной, созидательной, закрепительной [6, с. 9-11]. Оформление таблиц и иллюстраций, включающих микрофотографии изученных образцов, было сделано аналогично другим статьям автора по исследованным и опубликованным нео-энеолитическим памятникам, что необходимо для их сравнительного анализа.

В рамках подготовительной стадии гончарной технологии получена информация о виде и характере исходного пластичного сырья (ИПС), возможных источниках залежей этого сырья; способах его подготовки; традициях подготовки формовочных масс (ФМ).

По итогам микроскопического изучения керамики из энеолитических слоев Ракушечного Яра выделены два вида ИПС: иль и илистые глины. Детальное описание этих видов сырья и аргументация их выделения по археологической керамике неоднократно опубликованы [17]. Эти термины имеют условный характер и связаны со спецификой районов добычи природного пластичного сырья. К илам отнесено пластичное сырье, которое содержит в большой и средней концентрации растительные остатки: отпечатки водной растительности в виде нитевидных растений (водорослей) (рис. 1: 4); фрагменты листьев и стеблей различных растений (рис. 1: 1-3); немногочисленные фрагменты водной фауны: костей рыб (рис. 3: 3) и чешуи рыб (рис. 3: 1-2). В илах содержатся минеральные и органо-минеральные естественные компоненты: 1) фрагменты раковин пресноводных моллюсков (рис. 2: 4); 2) песок (рис. 1: 2); 3) различные включения железистых окислов (рис. 2: 5-6); 4) окатанные плотные нерастворившиеся комочки чистой глины (рис. 3: 4); 5) глинистые конкреции, насыщенные окислами железа (рис. 2: 6); 6) мелкие аморфные карбонатные включения белого цвета. Качественный состав илистых глин близок илам, отличия состоят в значительно меньшей концентрации и измельченности растительных остатков наземного и водного характера (рис. 3: 3-5).

В табл. 1 представлены итоги изучения представлений энеолитического населения Ракушечного Яра об ИПС как сырье для бытовой посуды (в подсчетах использованы единые относительные единицы проценты) (табл. 1). Она показывает, что немногочисленная выборка сосудов из слоя 5-5a сделана только из илов, а на современном этапе исследования появление посуды из илистых глин фиксируется в слое 4. В целом, совокупность сосудов из энеолитических слоев Ракушечного Яра, изготовленных из ила, составляет $60 \%$, а из илистых глин $-40 \%$. При этом фиксируется определенная динамика: керамика, сделанная из илов, составляет в слое $4-74 \%$, в слое $3-43 \%$, в слое $2-21 \%$. Соответственно увеличивается количество посуды, в качестве сырья для которой использовались илистые глины. Напомним, что керамика из неолитического слоя (слои 23-6) Ракушечного Яра полностью была изготовлена из илов [14]. 
Васильева И.Н.

О технологии изготовления керамики из энеолитических слоев поселения... $07.00 .00-$ исторические науки и археология
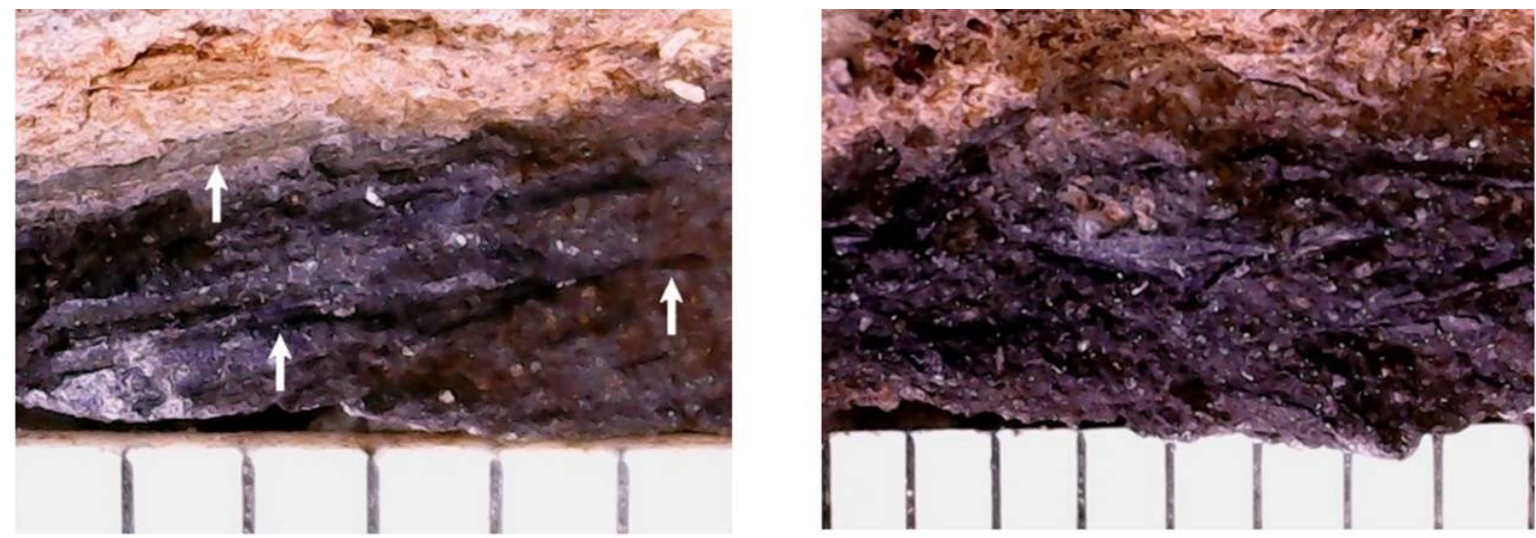

1
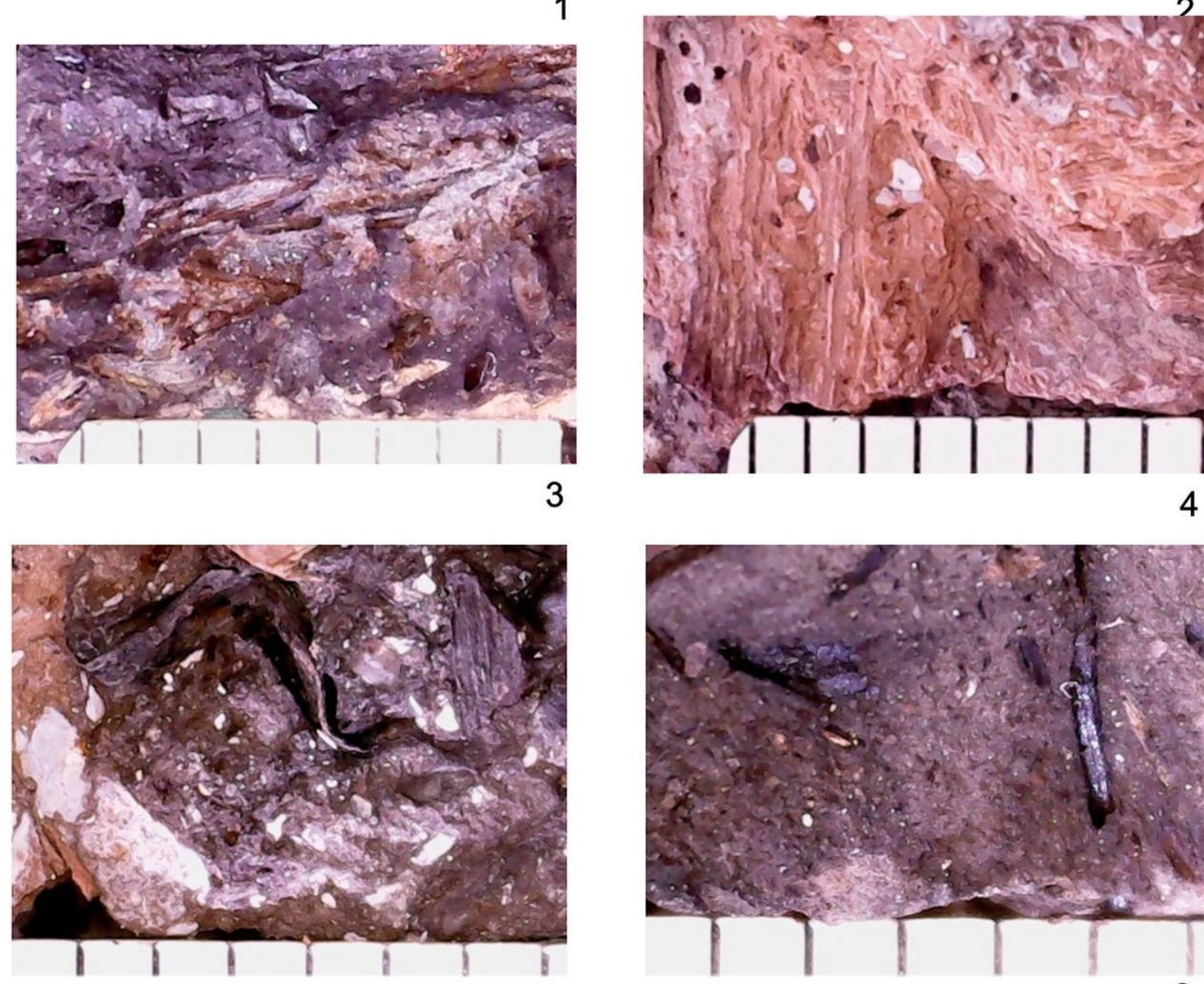

5

6

Рисунок 1 - Микрофотография керамики из энеолитических слоев поселения Ракушечный Яр. Отпечатки и углефицированные остатки растительности в исходном пластичном сырье: 1-6- в илах

Таблица 1 - Исходное пластичное сырье керамики из энеолитических слоев поселения Ракушечный Яр

\begin{tabular}{|c|c|c|c|c|c|c|c|c|c|c|c|}
\hline \multirow{4}{*}{ Слои } & \multicolumn{10}{|c|}{ Виды исходного пластичного сырья } & \multirow{4}{*}{ Всего: } \\
\hline & \multicolumn{5}{|c|}{ Илы } & \multicolumn{5}{|c|}{ Илистые глины } & \\
\hline & \multicolumn{2}{|c|}{ тощие } & \multicolumn{2}{|c|}{ жирные } & \multirow{2}{*}{ Всего: } & \multicolumn{2}{|c|}{ тощие } & \multicolumn{2}{|c|}{ жирные } & \multirow{2}{*}{ Всего: } & \\
\hline & рак. & $\sigma / p$ & рак. & $\sigma / p$ & & рак. & $6 / \mathrm{p}$ & рак. & $6 / p$ & & \\
\hline 2 & - & 2 & 3 & 1 & $6 / 21 \%$ & 1 & 1 & 15 & 6 & $23 / 79 \%$ & $29 / 100 \%$ \\
\hline 3 & 1 & 1 & 5 & 5 & $12 / 43 \%$ & - & - & 15 & 1 & $16 / 57 \%$ & $28 / 100 \%$ \\
\hline 4 & 2 & 26 & 14 & 9 & $51 / 74 \%$ & - & - & 2 & 16 & $18 / 26 \%$ & $69 / 100 \%$ \\
\hline $5-5 a$ & 2 & 7 & 2 & 4 & $15 / 100 \%$ & - & - & - & - & - & $15 / 100 \%$ \\
\hline \multirow{2}{*}{ Итого: } & 5 & 36 & 24 & 19 & \multirow{2}{*}{$\begin{array}{c}84 / 60 \% \\
100 \%\end{array}$} & 1 & 1 & 32 & 23 & \multirow{2}{*}{$\begin{array}{c}57 / 40 \% \\
100 \% \\
\end{array}$} & \multirow{2}{*}{$\begin{array}{c}141 \\
100 \% \\
\end{array}$} \\
\hline & \multicolumn{2}{|c|}{$41 / 49 \%$} & \multicolumn{2}{|c|}{$43 / 51 \%$} & & \multicolumn{2}{|c|}{$2 / 3 \%$} & \multicolumn{2}{|c|}{$55 / 97 \%$} & & \\
\hline
\end{tabular}

Примечания. Единица изучения - образец (отдельный сосуд); рак. - ИПС с естественной раковиной; б/p ИПС без естественной раковины. 
Следующий уровень дифференциации навыков отбора сырья связан со степенью запесоченности сырья. Для этого виды ИПС разделены на два подвида: тощие и жирные. По данным исследования этнографического гончарства известно, что для гончаров чистота или отощенность (запесоченность) глиняного сырья наряду с его цветом имела очень большое значение [4, с. 76, 81-82]. В современной исследовательской практике распространена оценка естественной песчаной примеси по подсчетам зерен песка на 1 кв. см и разделение материала на незапесоченные, слабозапесоченные, среднезапесоченные и сильнозапесоченные подвиды. В исследовании неолитической керамики нами используется более общий подход: к тощим подвидам ИПС отнесены сильно- и среднезапесоченные (рис. 2: 1-2), к жирным - слабозапесоченные и незапесоченные (рис. 2: 3-4). В ИПС керамики Ракушечного Яра выявлен пылевидный пе-
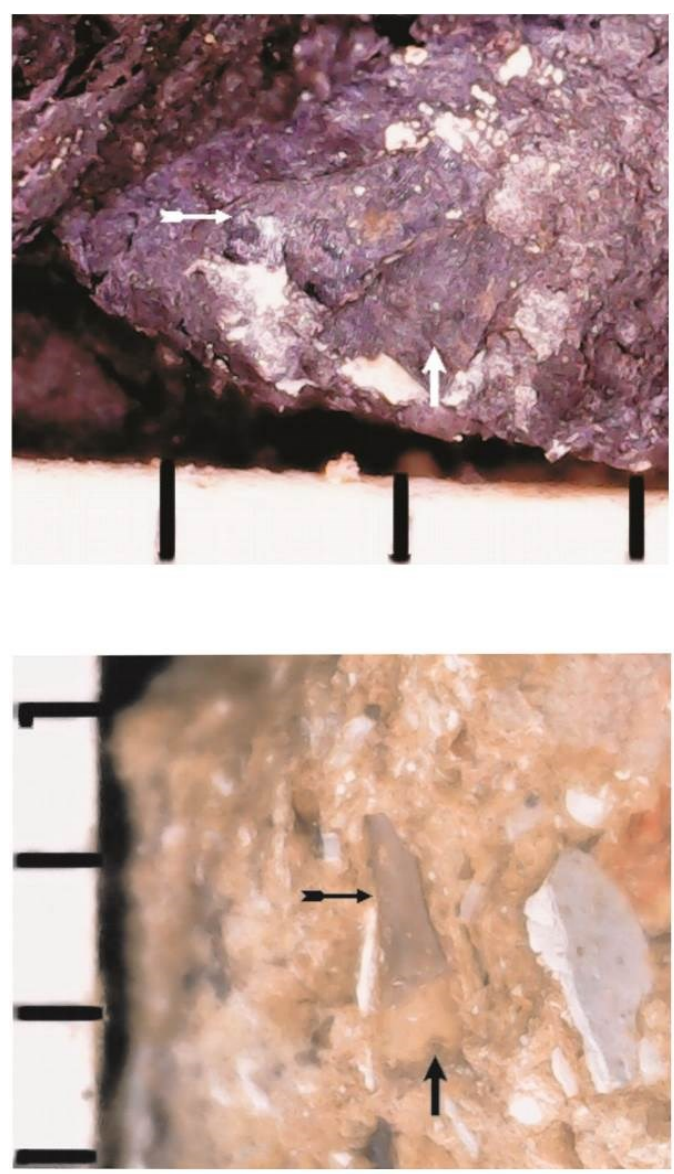

3

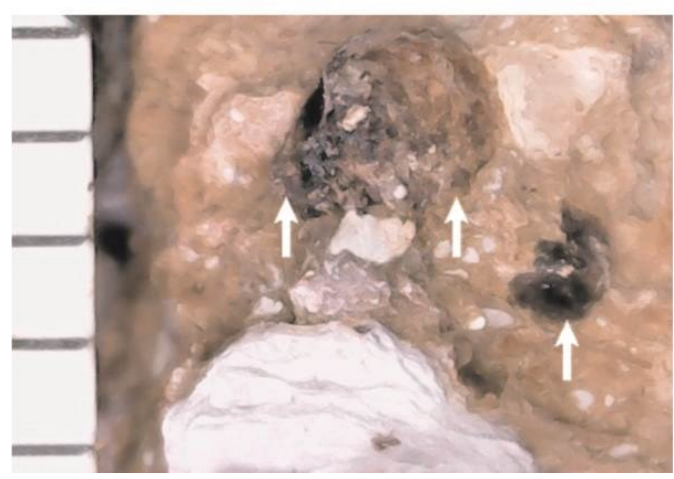

5

Рисунок 2 - Микрофотография керамики из энеолитических слоев поселения Ракушечный Яр.

Естественные минеральные, органо-минеральные и органические компоненты в илах и илистых глинах:

1-2 - остатки чешуи рыб; 3- кость рыбы; 4- включение раковины пресноводных моллюсков; 5- оолитовый бурый железняк; 6- железистая конкреция

сок (алеврит) и кварцевый окатанный и полуокатанный песок с размером частиц $0,1-0,3$ мм, реже - 0,51 мм. Результаты изучения энеолитической керамики Ракушечного Яра в целом указывают на сосуществование двух традиций отбора ИПС: тощего и жирного. Однако сравнение по видам ИПС убедительно свидетельствует о том, что при отборе илистых глин наиболее массовой была традиция использования жирных илистых глин (97\%), а при добыче илов приемы отбора тощих и жирных илов были распространены практически равномерно (49\% - тощих; $51 \%$ - жирных) (табл. 1). В гончарстве неолитического населения Ракушечного Яра приемы отбора жирных илов имели некоторое преимущество: тощие илы - 43\%, жирные илы - 57\% [14]. Можно предполагать, что в период энеолита в гончарстве населения стоянки имела место тенденция увеличения приемов отбора тощих илов.

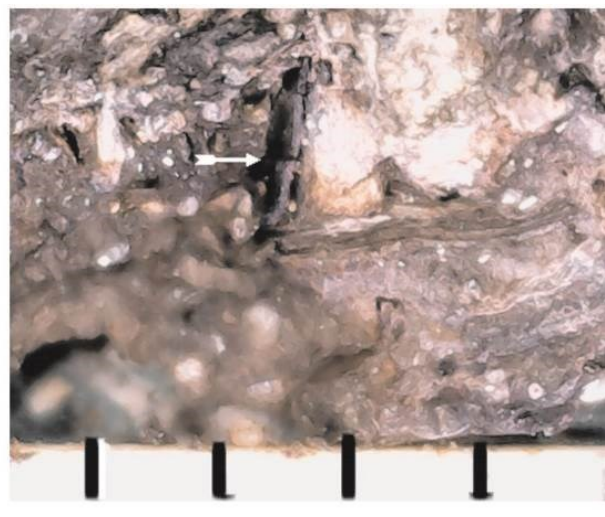

2

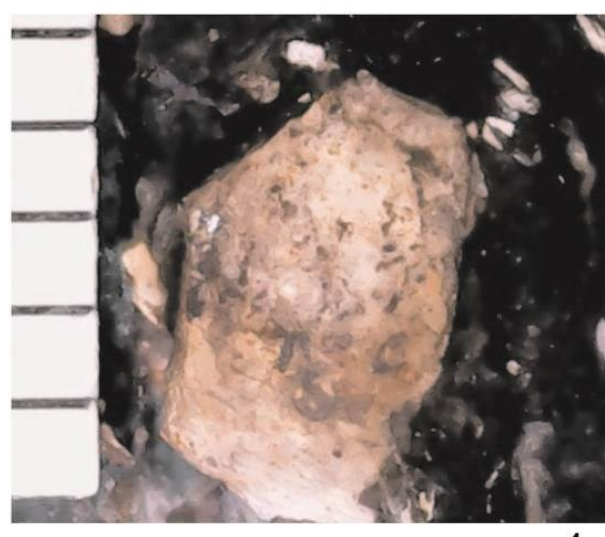

4

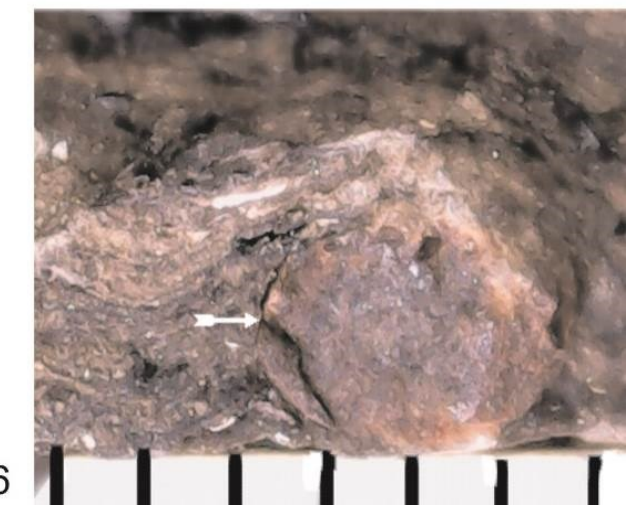

6

\author{
(n)
} .

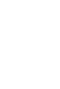


Характеристика приемов труда энеолитических гончаров Ракушечного Яра на подготовительной стадии гончарного производства будет неполной без учета информации о вариантах ИПС, которые определяются по наличию или отсутствию такого естественного спутника залежей сырья, как включения раковин пресноводных моллюсков. Этот показатель очень важен для илов, в которых обломки ракушки имеют однозначно естественный характер [4, с. 80 81]. Переход к другому виду ИПС - илистым глинам сопровождался изменением состава ФМ: к сырью стали добавлять искусственную примесь дробленой раковины. В этом случае в общем объеме раковины в черепке зачастую трудно вычленять именно естественные включения, хотя это иногда удается благодаря особенностям формы и состояния обломков ракушки (рис. 2: 4). Сам факт существования такой традиции составления ФМ говорит о большой культурной значимости примеси раковины в бытовой посуде, которая ей придавалась в представлениях энеолитических групп населения. Что касается илов, то согласно табл. 1 отбор тощих илов с раковиной составлял $12 \%$ (от количества сосудов, сделанных из тощих илов), а жирных илов с раковиной $-56 \%$ (от количества сосудов, изготовленных из жирных илов). Эти наблюдения имеют большое значение при сравнении с неолитической гончарной технологией, для которой были характерны следующие показатели: доля тощих илов с раковиной составляла $6 \%$, доля жирных илов с раковиной - всего $17 \%$. Полученные данные свидетельствуют о существенном увеличении приемов отбора илов с естественной примесью ракушки в период энеолита.

Изучение качественного состава илов и илистых глин, в том числе выявленная специфика естественных минеральных и органических компонентов, указывает на наличие многочисленных мест отбора ИПС рядом с поселением Ракушечный Яр. Кратковременный осмотр острова Поречный летом 2018 г. показал, что вероятность существования на нем источников илистого сырья вполне реальна. Остров окружен р. Дон, дно которого сильно заилено, на песчаном берегу повсеместно встречаются желваки жирной глины, вымытой из берега, на самом острове есть небольшие водоемы, окруженные заиленными участками. Более детально этот вопрос был исследован А.Н. Мазуркевичем, Е.В. Долбуновой, М.А. Кульковой [18]. Петрографический анализ керамики Ракушечный Яр, осуществленный М.А. Кульковой, подтвердил наличие нескольких источников пластичного сырья [18].

Установление характера сырья (сухого или влажного), в котором оно находилось непосредственно перед составлением формовочных масс, необходимо для выявления специфики приемов труда на этой ступени гончарной технологии, а также для последующих подсчетов концентрации искусственных примесей. В настоящее время можно зафиксировать сырье, дробленое в сухом виде (по нерастворившимся комочкам глины, линзам и потекам глины разной цветности и др.) [4]. По данным микроскопического изучения керамики из энеолитических слоев Ракушечного Яра можно предполагать, что основная часть илов и илистых глин использовалась в естественно-увлажненном состоянии. Единичные сосу- ды, изготовленные из илистых жирных глин, содержали в черепке наряду с нерастворившимися комочками чистой глины еще и ее вытянутые линзы (рис. 3: 3). Эти признаки указывают на вероятность применения приемов дробления ИПС в энеолитических гончарствах. Но они не получили большого распространения.

Для характеристики гончарных традиций на ступени составления формовочных масс (ФМ) изученный материал был разделен на 2 группы: 1) керамику, сделанную из илов, которые выступали в роли моносырья; 2) сосуды из илистых глин как основного сырья с искусственными примесями. К 1 группе относится большая часть керамики из энеолитических слоев Ракушечного Яра. Она была изготовлена в соответствии с двумя рецептами: 1) без каких-либо искусственных примесей и 2) с органическими растворами (ОР), которые являются, по-видимому, природными клеящими жидкими растительными или животными матриалами. Наличие органических растворов в черепке посуды определяется по щелевидным плоскостным или аморфным объемным пустотам размерами от 1 мм до 1 см, которые расположены как в середине, так и по краям черепка. На поверхности стенок этих пустот фиксируется налет вещества определенной плотности и цвета: молочнобелый (рис. 4: 5); маслянистый коричневато-черный; красновато-оранжевый (рис. 4; б); блестящие прозрачные пленки. По мнению А.А. Бобринского, органические растворы придавали изделиям свойства, связанные более с закрепительной стадией гончарной технологии (например, прочность), и история сложения данной традиции уходит корнями в догончарный период [6]. Следует отметить, что единичные сосуды из ила содержали, по-видимому, искусственно добавленную дробленую раковину, о чем свидетельствует концентрация и состояние раковинной примеси [14]. В рамках 2 группы керамики выделяются следующие рецепты ФМ: 1) илистые глины + дробленая раковина (ДР) + ОР (рис. 4: 6); 2) илистые глины + птичий пух (ПП) + ДР + ОР (рис. 4: 1-2). 3) илистые глины + песок (П) + ДР + ОР (рис. 4: 3-4). В слое 2 найдено два фрагмента сосудов с шамотом. По-видимому, они относятся к эпохе бронзы и далее в данной статье не рассматриваются.

Следует подробнее остановиться на описании искусственных материалов, которые использовались при подготовке ФМ. Примесь дробленой раковины вводилась в ФМ в условно средней и большой концентрации [14]. Обломки раковины имели дымчатосерый сквозной цвет и перламутровый блеск, что говорит о ее предварительной подготовке (нагревании ее на углях, в закрытых условиях, при восстановительной атмосфере) и об отборе свежей раковины, а не старой, находившейся долгое время на солнце на берегах водоемов. Энеолитическими гончарами использовался кварцевый окатанный песок с размером частиц 0,5-1,5 мм (рис. 4: 3). Он вводился в ФМ в концентрации 1:4-1:6. Птичий пух обладает специфичными внешними признаками, что избавляет от необходимости его подробного описания (рис. 4: 12). Концентрация птичьего пуха различна: в небольшой части сосудов он представлен единичными включениями, но в основном - существенным количеством. 
Табл. 2 отражает количественную представленность рецептов ФМ керамики Ракушечного Яра по изученным материалам. Она подтверждает, что основная часть посуды из энеолитических слоев Ракушечного Яра была сделана в соответствии с двумя традициями составления ФМ, о чем было написано выше: 1) ил с ОР или без каких-либо искусственных добавок (55,6\% от всего количества изученной керамики); 2) илистые глины с добавкой ДР + ОР (25\% от всего количества изученной керамики); с ДР + ОР и птичьим пухом (8\%); с ДР + ОР + песком (10\%) суммарно около 44-45\% (если исключить сосуды с шамотом, которые скорее всего относятся к слою

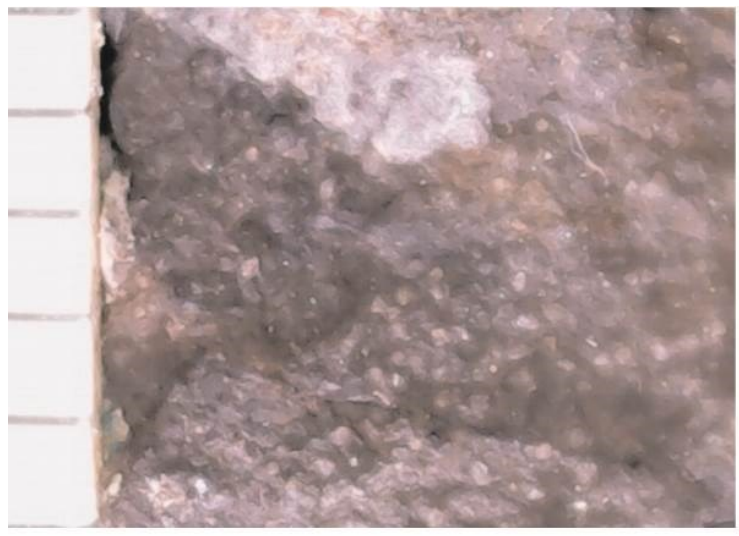

1

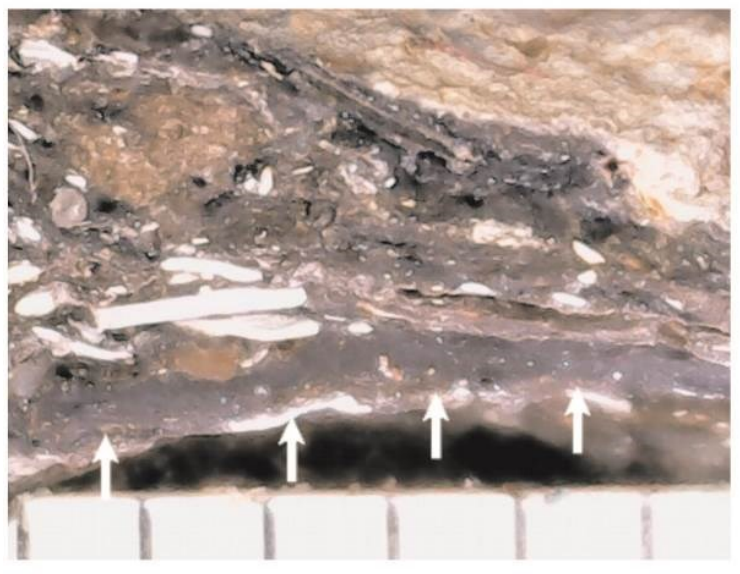

3

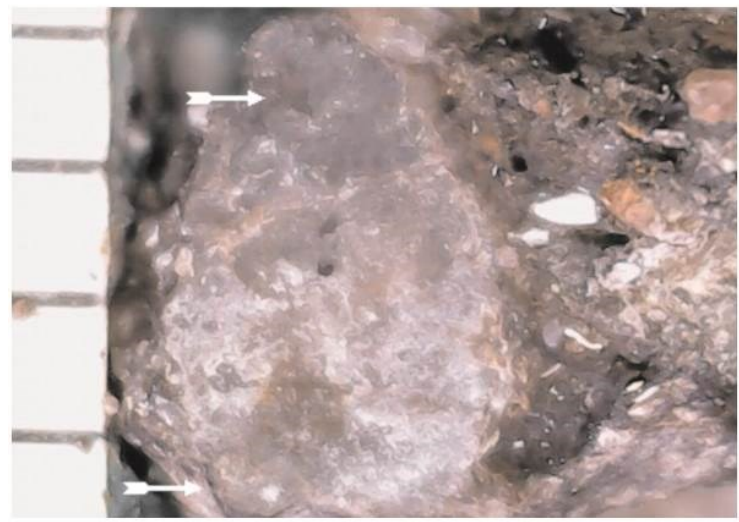

5 бронзового века). Таким образом, можно говорить, что первая традиция была более массовой, но вторая также была распространенной. При этом обращает на себя существование смешанных рецептов, включавших кроме ДР еще и другие добавки: птичий пух и песок. Можно констатировать, что первая традиция составления ФМ из илов без примесей или только с ОР уходит корнями в гончарство неолитического населения Ракушечного Яра. Традиции использования илистых глин и введения в ФМ искусственных (органических, органо-минеральных и минеральных) добавок появились у населения стоянки только в эпоху энеолита [14].

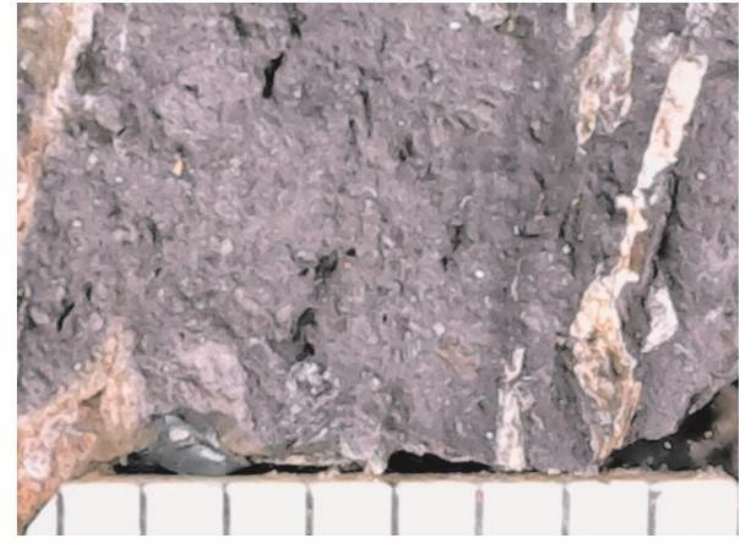

2

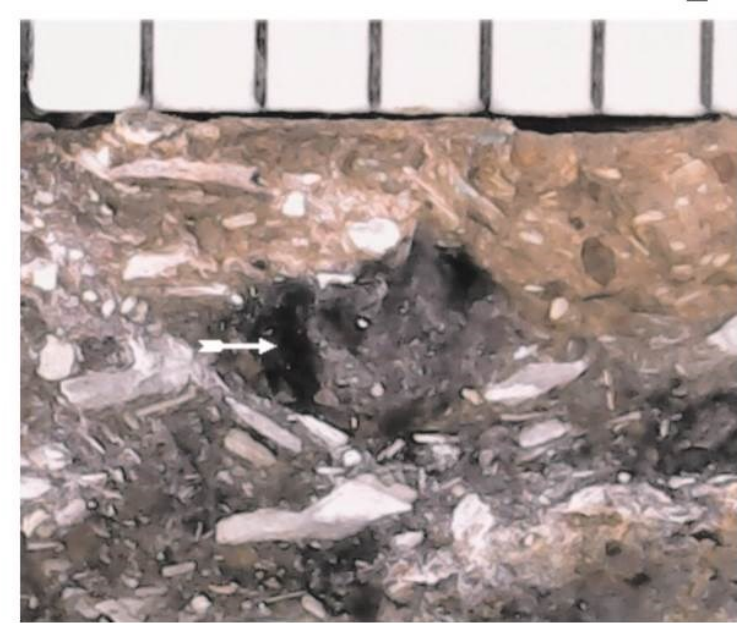

4

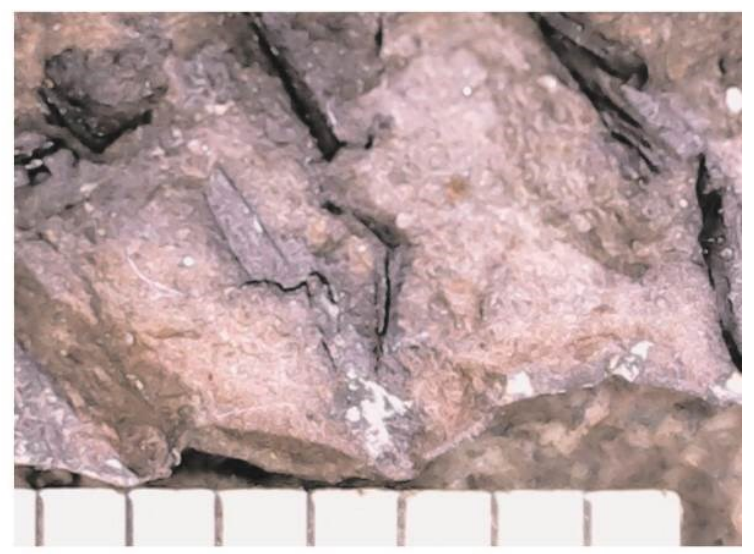

6

Рисунок 3 - Микрофотография керамики из энеолитических слоев поселения Ракушечный Яр. Исходное пластичное сырье: 1 - тощая илистая глина; 2, 6-жирные илы;

3- илистая глина, дробленая в сухом состоянии; 4- комочек не растворившейся илистой глины; 5- отпечаток чешуи рыбы (ИПС - илистая глина) 
Васильева И.Н.

О технологии изготовления керамики из энеолитических слоев поселения... $07.00 .00-$ исторические науки и археология
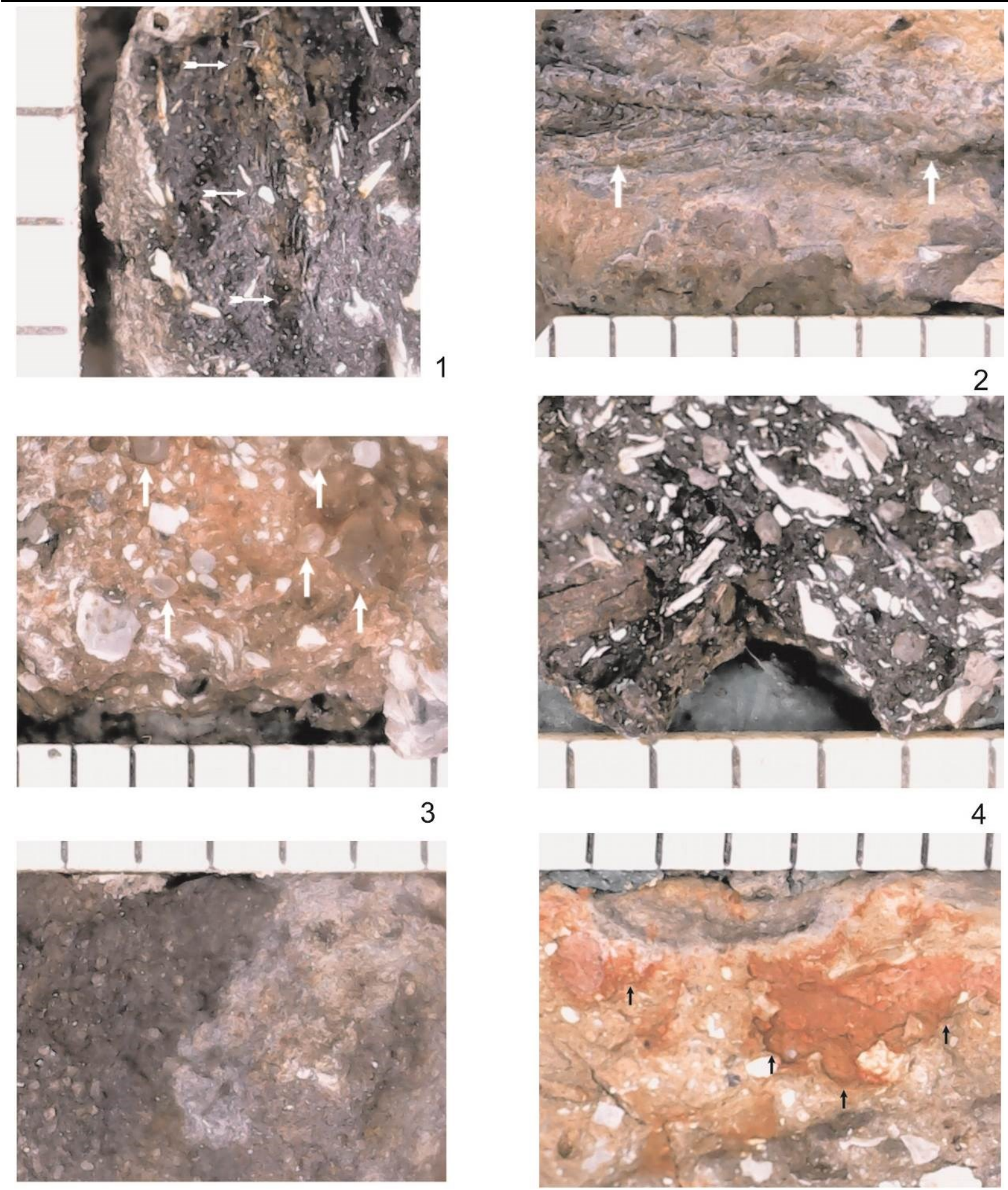

5

Рисунок 4 - Микрофотография керамики из энеолитических слоев поселения Ракушечный Яр. Искусственные компоненты формовочных масс: 1-2- отпечатки пуха птиц; 3-4- дробленая раковина и песок; 5-6- органический раствор

Таблица 2 - Формовочные массы керамики из энеолитических слоев поселения Ракушечный Яр

\begin{tabular}{|c|c|c|c|c|c|c|c|c|}
\hline \multirow{2}{*}{ Слои } & \multicolumn{7}{|c|}{ Формовочные массы } & \multirow{2}{*}{ Итого: } \\
\cline { 2 - 8 } & б/пр & ОР & ДР + ОР & ДР + ПП + ОР & ДР + П ОР & П + Ш & ОР + Ш & 29 \\
\hline 2 & - & 8 & 10 & - & 9 & 1 & 1 & 28 \\
\hline 3 & - & 9 & 13 & 6 & - & - & - & 69 \\
\hline 4 & 3 & 46 & 9 & 6 & 5 & - & - & 15 \\
\hline $5-5 \mathrm{a}$ & 5 & 7 & 3 & - & - & - & - & $141 / 100 \%$ \\
\hline Всего & $8 / 5,6 \%$ & $70 / 50 \%$ & $35 / 25 \%$ & $12 / 8 \%$ & $14 / 10 \%$ & $1 / 0,7 \%$ & $1 / 0,7 \%$ & $14 \%$ \\
\hline
\end{tabular}

Примечания. Единица изучения - образец (отдельный сосуд); OP - органический раствор; б/np. - без искусственных примесей; ДР - дробленая раковина; ПП - пух птиц; П - песок; $U$ - шамот. 
Характеристика приемов труда на созидательной стадии гончарного производства имеет общий характер из-за существенной фрагментированности изученного материала. Основываясь на совокупности признаков лоскутного налепа, можно констатировать его применение на ступенях конструирования как начинов, так и полого тела [19]. Обращает на себя внимание присутствие в керамическом комплексе энеолитических слоев Ракушечного Яра плоских, уплощенных и единичных конических днищ, при преобладании первых. Навыки изготовления донных частей сосудов, независимо от формы, были связаны с использованием лоскутного налепа. В процессе создания сосудов, изготовленных как из ила, так и из илистых глин, использовались два основных способа: 1) лоскутный комковатый, с бессистемным, иногда многослойным, наложением строительных элементов (расплющенных комочков ФМ) и размазыванием их по твердой модели; 2) налеп, производившийся по круговой и спиральной траектории из лоскутов (коротких жгутов, отрываемых от более длинного жгута). Их приблизительные размеры: диаметр не более 1-1,5 cм, длина 3-5 см. Можно отметить, что первый способ чаще применялся в гончарствах, основанных на илах. Небольшая часть изученных сосудов обнаружила признаки зонального лоскутного налепа, при котором наращивание лоскутков производилось для создания колец или зон, из которых поэтапно строились стенки сосудов. Зафиксированная высота этих зон: 3-4 см. Приемы формообразования были связаны с использованием различных форммоделей и выбиванием. Обработка поверхностей производилась посредством заглаживания мягкими материалами и твердыми орудиями, а также уплотнения (по влажной поверхности) и лощения (по подсушенной поверхности). Изучение неолитической керамики показало, что с самого нижнего 23 слоя стоянки Ракушечный Яр в гончарстве ее населения применялся прием заглаживания твердым орудием, оставившим ровные параллельные бороздки аналогично гребенчатому штампу (подобные следы могли оставить некоторые виды раковин с ребристыми краями) [14]. Традиция обработки поверхностей таким орудием сохранялась в энеолитический период. Заглаживанию подобными орудиями подвергалась преимущественно внутренняя поверхность сосудов, иногда фрагментарно и внешняя поверхность. Следует отметить, что такой прием обработки поверхностей зафиксирован как на посуде, сделанной из ила, так и на сосудах, изготовленных из илистых глин с разными минеральными и органическими добавками.

Навыки придания прочности и водонепроницаемости изделиям на закрепительной стадии гончарной технологии были связаны прежде всего с термической обработкой. Поверхность сосудов из энеолитических слоев Ракушечного Яра имеет в основном пятнистую серо-коричневую окраску. Выделяются следующие виды излома черепка: 1) однотонный серый или черный; 2) трехслойный (с осветленными поверхностными прослоями и темно-серой сердцевиной); 3) двухслойный (со светло-коричневым прослоем у внешней или внутренней поверхности и темно-серой остальной частью черепка). Распространение такого вида пятнистости цвета поверхностей посуды и 2-3-слойных изломов указывает на применение приемов неполной выдержки изделий при температурах каления глины, в условиях неста- бильной газовой среды. Известно, что раковина сохраняется в черепке сосудов только при обжиге в низких температурах (не более 700-750) в сочетании с кратковременной выдержкой при этих температурах. В сосудах, обожженных при более высоких температурах и длительной выдержке, включения раковин, как правило, разрушаются. Обращает на себя внимание, что в энеолитических слоях Ракушечного Яр наблюдается большее количество сосудов с темной окраской поверхностей, чем в неолитическом слое. Не следует забывать об архаичной традиции введения в ФМ органических растворов, которые появились в догончарный период и были направлены на придание изделиям прочности. По этим причинам А.А. Бобринский отнес их к «холодным» способам придания прочности [6, с. 85-105]. Таким образом, можно констатировать распространение среди гончаров Ракушечного Яра в энеолитический период смешанных способов придания прочности и влагонепроницаемости сосудов: холодных и горячих (термических) воздействий на гончарные изделия. По итогам изучения навыки труда энеолитических гончаров Ракушечного Яра на закрепительной стадии можно относить к частично сформированным [6, c. $85-89,105]$.

Обобщение полученных данных дало возможность оконтурить совокупность технологических традиций, получивших массовое распространение в гончарстве населения Ракушечного Яра в период энеолита.

Подготовительная стадия: 1) сосуществование представлений об илах и илистых глинах как пластического сырья для изготовления бытовой посуды; 2) в гончарствах, основанных на илах, - почти равное распространение приемов отбор тощих и жирных подвидов; в гончарствах, связанных с илистыми глинами - преимущественное использование жирных подвидов; 3) увеличение приемов отбора илов с визуально фиксируемыми обломками естественной ракушки (по сравнению с неолитом); 4) естественно увлажненное состояние ИПС непосредственно перед составлением ФМ; появление приемов дробления жирных илистых глин в сухом виде; 5) сосуществование двух основных традиций составления формовочных масс: 1) ил с ОР или без каких-либо искусственных добавок, т.е. ИПС выступает в роли моносырья; 2) илистые глины в качестве основного сырья с искусственными добавками: дробленой раковиной, органическим раствором, птичьим пухом и песком.

Созидательная стадия: 1) широкое распространение приемов лоскутного налепа; 2) бессистемное, спиралевидное и кольцевидное наращивание строительных элементов - комков и лоскутков; зональный лоскутный налеп; 3) использование форм-моделей и выбивания на ступени формообразования; 4) простое механическое заглаживание поверхностей сосудов твердыми предметами и мягкими материалами; уплотнение и лощение.

Закрепительная стадия: 1) применение смешанных (горячих и холодных) приемов придания прочности и влагонепроницаемости сосудам; 2) распространение приемов термической обработки, связанных с длительным периодом пребывания изделий в зоне действия невысоких температур в восстановительной среде; 3) соответствие представлений о термической обработке состоянию частичной сформированности $[6$, c. 89,102$]$. 
Характеризуя в целом энеолитическую гончарную технологию, можно отметить, что в этот период на поселении сохранялись производства бытовой керамики без орнамента, которые имели простейшую структуру (10 обязательных ступеней), однако получили большее распространение гончарные производства, имевшие простую структуру (10 обязательных и одну дополнительную ступень - орнаментирование) [6, с. 11]. Т.Д. Белановская отмечает значительное увеличение в верхних слоях стоянки орнаментированной керамики [15, с. 117-120]. Оба вида производств относятся к протогончарным, если илы в них выполняли функцию пластичного моносырья [6, с. 79]. Протогончарные производства обнаруживают устойчивую связь с неолитическим гончарством [14]. В то же время появились новые производства с простой структурой: в некоторых из них наблюдается использование илов в качестве основного сырья и добавки к ним искусственной, специально подготовленной дробленой раковины (протогончарное производство: ПГ-8). Более многочисленная группа энеолитических производств бытовой посуды на Ракушечном Яре обнаруживает признаки освоения другого вида ИПС - илистых глин. При подготовке ФМ илистые глины смешивались с органо-минеральной примесью (дробленой раковиной), органической (пух птиц), минеральной (песком). При этом илистые глины выполняли функцию основного пластичного сырья в сочетании с искусственными добавками (архегончарное производство) [6, с. 84]. Выявление разных по уровню и структуре гончарных производств на одном поселении указывает на глубокие культурные различия между носителями гончарных традиций.

\section{Обсуждение результатов}

Интерпретация данных о гончарной технологии основывается на закономерностях, выявленных в результате обобщения многочисленных этнографических и археологических данных: 1) об исторически складывающейся системе трудовых навыков в гончарстве; 2) о сохранении их в стабильных условиях и различном поведения в ситуациях смешения культурных групп населения; 3) о механизме передачи навыков труда в традиционных обществах только эмпирическим путем, по родственным каналам, из поколения в поколение, приводившем к устойчивости и консерватизму культурных традиций в гончарном производстве [4]. Информация о гончарной технологии населения Ракушечного Яра в период энеолита может быть использована в разработке вопросов историко-культурного характера, в частности в выявлении преемственности культурных традиций населения стоянки в периоды неолита и энеолита, а также гомогенности энеолитических коллективов.

Сравнительный анализ данных по ИПС и ФМ керамики разных хронологических периодов бытования поселения Ракушечный Яр привел к результатам, обобщенным в табл. 3 (из анализа были исключены сосуды с шамотом (по названным причинам).

Табл. 3 убедительно демонстрирует, с одной стороны, черты преемственности между неолитическим и одной группой энеолитического населения, с другой стороны - существенные изменения, произошедшие в гончарстве в энеолитический период. Можно предполагать, что в энеолите на поселении Ракушечный продолжало бытовать население, гончарные традиции которого были связаны с неолитическими, но появились и новые производства бытовой посуды, существенно отличные от предыдущего времени. Для них были характерны другие представления об ИПС (появился новый вид ИПС - илистые глины). Изменилась функция пластичного сырья: оно стало выполнять роль не моносырья, а основного сырья с сочетанием искусственных добавок, что свидетельствует о различных уровнях изучаемых гончарных производств: первые относятся к протогончарным, вторые - к архегончарным [6, с. 84]. К этому следует добавить, что в рамках протогончарных производств преобладала простейшая структура гончарной технологии, а в архегончарных - простая структура. Состав орнаментальных традиций в энеолитический период стал значительно разнообразнее. Определенные изменения зафиксированы в способах придания прочности, в частности в режимах обжига изделий, которые в энеолите были более приспособлены к специфике термической обработки сосудов, содержащих раковину. Таким образом, по данным изучения технологии изготовления керамики можно констатировать значительные изменения гончарных традиций части населения Ракушечного Яра в период энеолита.

Важным является выяснение характера зафиксированных нами изменений. Они могли иметь эволюционный или конкретно-исторический характер. В первом случае можно прийти к выводу о формировании нижнедонской культуры на основе ракушечноярской, как это делает Н.С. Котова [16, с. 28]. Во втором случае - предполагать появление в энеолите на острове Поречный новых культурных групп и сосуществование их с местным неолитическим населением. Как известно, эволюционные изменения происходят в результате накопления коллективного опыта в течение многих поколений, которое в конечном итоге приводит к качественным изменениям навыков труда в гончарстве. Эволюционные изменения имеют однонаправленную тенденцию в развитии и действуют постоянно в любых гончарных производствах. Конкретно-исторические процессы в гончарстве возникают в отдельных регионах в разные хронологические периоды, действуют в течение жизни одного или нескольких поколений, могут быстро прекращаться и возобновляться, и всегда нарушают ход естественного развития человеческой деятельности [20].

таблица 3 - Результаты сравнительного анализа исходного пластичного сырья и формовочных масс керамики неолита и энеолита поселения Ракушечный Яр

\begin{tabular}{|c|c|c|c|c|c|c|c|c|}
\hline \multirow{2}{*}{ Периоды } & \multicolumn{2}{|c|}{ Виды ИПС } & \multicolumn{5}{|c|}{ Формовочные массы } & \multirow{2}{*}{ Всего: } \\
\hline & Илы & Илистые глины & б/пр. & OP & ДР + ОР & ДР + ОР + ПП & ДР + OP + П & \\
\hline Неолит & $100 \%$ & - & 55 & 156 & - & - & - & 211 \\
\hline Итого: & & & \multicolumn{2}{|c|}{$211 / 100 \%$} & \multicolumn{3}{|c|}{-} & $100 \%$ \\
\hline Энеолит & $60 \%$ & $40 \%$ & 8 & 70 & 35 & 12 & 14 & 139 \\
\hline Итого: & & & \multicolumn{2}{|c|}{$78 / 56 \%$} & \multicolumn{3}{|c|}{$61 / 44 \%$} & $100 \%$ \\
\hline
\end{tabular}

Примечания. Единица изучения - образец (отдельный сосуд); ИПС - исходное пластичное сырье; $О Р$ органический раствор; б/np. - без искусственных примесей; ДР- дробленая раковина; ПП - пух птиц; П - песок. 
Делая вывод об эволюционном изменении представлений об ИПС, переходе от илов к илистым глинам и одновременном формировании традиции введения в ФМ дробленой раковины в среде населения неолитической орловской культуры в степном Нижнем Поволжье [21], мы опирались на: 1) отсутствие существенных различий в формах и орнаментации керамики, изготовленной из того и другого вида ИПС; 2) данные стратиграфии и абсолютного датировании слоев Варфоломеевской стоянки; 3) археологический контекст. Исследователь Варфоломеевской стоянки А.И. Юдин всесторонне проанализировал археологические источники и пришел к выводу, что «литологические слои памятника отражают последовательное развитие одной неолитической культуры при сохранении основных культуроопределяющих признаков на всем протяжении ее существования, а все выявленные изменения носят хронологический характер и в основных своих направлениях соответствуют аналогичным переменам в материальных комплексах сероглазовской и джангарской культур» [22]. Материалы поселения Ракушечный Яр показывают другую картину: существенные различия между керамикой из неолитических и энеолитических слоев Ракушечного Яра проявились в формах сосудов, в орнаментальных традициях и в гончарной технологии. Определенная специфика других вещественных комплексов стоянки периода энеолита была выявлена Т.Д. Белановской $[15$, с. 175]. Эти данные склоняют нас к выводу о конгломератном состоянии носителей разных культурных традиций на поселении Ракушечный Яр в период энеолита и начавшемся культурном смешении местного населения с пришлыми коллективами. Об этом свидетельствует совместное залегание керамики, сделанной из ила и илистой глины, в слоях 4-3; морфологическая близость части сосудов, изготовленных из ила и происходящих из этих слоев, с керамикой ракушечноярской неолитической культуры; наличие смешанных рецептов ФМ: ил + дробленая раковина.

Большой интерес представляет вопрос о гомогенности пришлых энеолитических коллективов и возможных истоках их гончарных традиций. Выявленное разнообразие рецептов ФМ (табл. 2-3) несомненно указывает на неоднородность энеолитических групп населения: в качестве примеси к сырью они добавляли дробленую раковину, птичий пух, песок. Корреляция морфологических особенностей сосудов с разными искусственными примесями ФМ дала следующие результаты. Из илов изготовлены преимущественно плоскодонные толстостенные сосуды, хотя единично встречаются изделия с конусовидным днищем. Среди них имеются неорнаментированные сосуды, преобладает техника нанесения узоров посредством накалывания, накалывания с отступанием, реже - штампования гладким и гребенчатым штампом. На некоторых изделиях встречается сочетание техник: гребенчатой с накалыванием и прочерчиванием. В посуде из илистых глин с искусственными добавками преобладают сосуды с выделенной шеей, иногда с наплывом с внутренней стороны и воротничком снаружи. В орнаментальных традициях фиксируется преобладание приемов штампования разными гребенчатыми штампами, часто в сочетании с прочерченными ломаными линия- ми. Можно отметить значительную представленность ямчатого орнамента (в сочетании с другими) на изделиях, содержащих птичий пух, а также распространенность прочерченного орнамента на сосудах, изготовленных из илистых глин с добавкой дробленой раковины и песка.

Состояние изученности нео-энеолитической гончарной технологии Восточной Европы на современном этапе позволяет лишь наметить возможные истоки энеолитических гончарных традиций. А.А. Бобринским было сделано предположение о том, что традиции введения естественных или искусственно образованных (дробленых) примесей: песка, дресвы, раковины - могли появиться у носителей навыков использования илов по мере распространения гончарной технологии [6, с. 78]. Историю зарождения и распространения новых традиций в различных культурно-исторических зонах на ранних этапах гончарства предстоит только воссоздать, а для этого необходимо широкое исследование нео-энеолитической гончарной технологии Восточной Европы и других регионов совместно с радиоуглеродным датированием керамических комплексов. Можно отметить лишь установленные к настоящему времени (с помощью бинокулярной микроскопии) факты. В результате многолетних работ нами был выявлен и аргументирован факт формирования и распространения традиции отбора илистых (преимущественно жирных) глин и введения в них предварительно подготовленной примеси дробленой раковины - в рамках орловской культуры степного Поволжья. Посуда, сделанная по этой технологии, встречается уже в нижнем слое 3 Варфоломеевской стоянки [21]. Позднее, в эпоху энеолита данная традиция получила массовое распространение в гончарстве населения энеолитических: прикаспийской, хвалынской, частично самарской культур. Однако недавно в Подонье была исследована новая неолитическая стоянка Черкасская V. Микроскопическое изучение керамики позволило установить применение в процессе ее изготовления приемов, характерных для населения орловской культуры [12]. Остается практически неизученным по методике А.А. Бобринского нео-энеолитическое гончарство Крыма и Украины. Поэтому в настоящее время можно говорить лишь о вероятности зарождения традиции введения в ФМ дробленой раковины именно в Поволжье. Еще меньше информации о формировании традиции введения в ФМ песка. Исследование неолитического гончарства Подонья позволило нам зафиксировать факт массового использования тощих илистых глин и появления традиции добавления в ФМ искусственного крупного песка в рамках населения карамышевской и среднедонской культур [12]. Конкретизация этого процесса требует дальнейшего изучения. Проблема зарождения традиции введения птичьего пуха в ФМ древней керамики имеет солидную историографию [23]. Птичий пух как примесь был массово выявлен в керамике волосовской и имеркской энеолитических культур Примокшанья [23], а также в ФМ сосудов с внутренним ребром из энеолитических слоев стоянок Самарского Поволжья. Он известен в керамике культур эпохи неолита: Ю.Б. Цетлиным в свое время были выделены рецепты с птичьим пометом в керамике верхневолжской культуры, основным признаком ко- 
торого являются включения птичьего пуха [24]. К настоящему времени стало очевидным, что данный вопрос нуждается в разработке методики и расширении источниковой базы. В целом, можно отметить недостаточную проработанность археологических материалов эпохи неолита и энеолита Восточной Европы - периода, куда уходят корнями многие гончарные традиции, и вместе с тем перспективность исследований в этом направлении. Введение в научный оборот данных технико-технологического анализа энеолитической керамики поселения Ракушечный Яр будет этому способствовать.

\section{Список литературы:}

1. Городцов В.А. Русская доисторическая керамика. М.: Моск. арх. общество, 1901. 101 с.

2. Жуков Б.С. Теория хронологических и территориальных модификаций некоторых неолитических культур Восточной Европы по данным изучения керамики // Этнография. 1929. № 1. С. 54-77.

3. Фосс М.Е. Древнейшая история севера европейской части СССР // Материалы и исследования по археологии СССР. 1952. № 29. 280 с.

4. Бобринский А.А. Гончарство Восточной Европы. Источники и методы изучения. М.: Наука, 1978. 272 с.

5. Бобринский А.А. Гончарные мастерские и горны Восточной Европы (по материалам II-V вв. н.э.). М.: Наука, 1991. 211 с.

6. Бобринский А.А. Гончарная технология как объект историко-культурного изучения // Актуальные проблемы изучения древнего гончарства: кол. монография. Самара: Самарский ГПУ, 1999. С. 5-109.

7. Формы глиняных сосудов как объект изучения. Историко-культурный подход. М.: ИА РАН, 2018. $253 \mathrm{c}$.

8. Волкова Е.В. Историко-культурный подход к изучению орнаментов на древней глиняной посуде // Керамика как исторический источник. Подходы и методы изучения: тез. докл. всесоюз. науч. совещ. Свердловск, Куйбышев: Куйбышевский ГПИ, 1991. C. 31-34.

9. Цетлин Ю.Б. Неолит центра Русской равнины. Орнаментация керамики и методика периодизации культур. Тула: Гриф и К, 2008. 352 с.

10. Цетлин Ю.Б. Проблемы научного эксперимента в изучении древнего гончарства // Российская археология. 1995. № 2. С. 59-68.

11. Васильева И.Н., Салугина Н.П. Экспериментальный метод в изучении древнего гончарства (к проблеме разработки структуры научного исследования с использованием физического моделирования // Актуальные проблемы изучения древнего гончарства: кол. монография. Самара: Самарский ГПУ, 1999. С. 181-198.

12. Васильева И.Н. К вопросу о гончарных традициях неолитического населения Подонья // Известия
Самарского научного центра РАН. 2017. Т. 20, № 3. C. $370-379$.

13. Васильева И.Н. Гончарная технология ранненеолитического населения Подонья // Самарский научный вестник. 2017. Т. 6, № 3 (20). С. 109-123.

14. Васильева И.Н. Некоторые итоги техникотехнологического анализа керамики поселения Ракушечный Яр // Самарский научный вестник. 2018. Т. 7, № 3 (24). С. 137-153.

15. Белановская Т.Д. Из древнейшего прошлого Нижнего Подонья: Поселение времени неолита и энеолита Ракушечный Яр. СПб.: Изд-во С.-Петербургского ун-та, 1995. $199 \mathrm{c.}$

16. Котова Н.С. Неолитизация Украины. Луганск: Изд-во «Шлях», 2002. 268 с.

17. Васильева И.Н. О выделении видов исходного пластичного сырья древнейшей керамики и их ареалах в эпоху неолита (по материалам Поволжья) // Современные подходы к изучению древней керамики в археологии. М.: Изд-во ИА РАН, 2015. С. 16-23.

18. Мазуркевич А.Н., Долбунова Е.В., Кулькова М.А. Керамические традиции в раннем неолите Восточной Европы // Российский археологический ежегодник. № 3. СПб.: Изд-во «Университетский издательский консорциум, 2013. С. 27-109.

19. Васильева И.Н., Салугина Н.П. Лоскутный налеп // Древнее гончарство. Итоги и перспективы изучения. М.: Изд-во ИА РАН, 2010. С. 72-87.

20. Бобринский А.А., Васильева И.Н. О некоторых особенностях пластического сырья в истории гончарства // Проблемы древней истории Северного Прикаспия. Самара: Самарский ГПУ, 1998. С. 193-217.

21. Васильева И.Н. Об эволюции представлений о пластичном сырье в среде неолитического населения степного Поволжья (по материалам Варфоломеевской стоянки) // Проблемы изучения культур раннего бронзового века степной зоны Восточной Европы. Оренбург: Изд-во ОГПУ, 2009. С. 65-77.

22. Юдин А.И. Варфоломеевская стоянка и неолит степного Поволжья. Саратов: Изд-во Саратовского университета, 2004. 199 с.

23. Петряшов Д.В., Павлов С.И. К вопросу о примеси птичьего пуха в древней керамике Примокшанья // Историко-археологические изыскания: сборник трудов молодых ученых. Вып. 4. Самара: Самарский ГПУ, 2001. С. 63-71.

24. Цетлин Ю.Б. Периодизация неолита Верхнего Поволжья. Методические проблемы. М.: ИА АН CCCP, 1991. $195 \mathrm{c}$.

Работа подготовлена в рамках выполнения Государственного задания Минобрнауки РФ, проект № 33. 1907.2017/ПЧ «Традиционнье и инновационные модели развития древнего населения Поволжья".

\section{CERAMICS MAKING TECHNOLOGY FROM THE ENEOLITHIC LAYERS OF RAKUSHECHNY YAR SETTLEMENT}

(C) 2019

Vasilieva Irina Nikolaevna, candidate of historical sciences, senior researcher of Research Department Samara State University of Social Sciences and Education (Samara, Russian Federation)

Abstract. The paper contains the results of the technical and technological analysis of ceramics from the Eneolithic layers of the Rakushechny Yar settlement. It is located on the Porechny Island (the Don River, Rostov Region, Russian Federation). The methodological basis of the conducted research is a historical and cultural approach to the 
study of ancient ceramics, developed in Russian archeology by A.A. Bobrinsky. The methods of the research are binocular microscopy, trasology and experiment (physical modeling). 141 samples of ceramics (conditionally separate vessels) from layers 5-2 of Rakushechny Yar were subjected to a microscopic examination. The obtained technological information allowed us to reconstruct techniques and methods of Eneolithic utensils manufacturing at all stages of production - preparatory, creative and fortifying stages of pottery technology. Based on these data, the paper presents a general description of the Eneolithic pottery. A comparative analysis was made of the pottery technology of the Neolithic and Eneolithic population that inhabited the Rakushechny Yar site. According to its results, the similarities and differences of the Eneolithic and Neolithic pottery traditions are highlighted. Particular attention is paid to the question of the possible origins of new traditions, which became widespread during the Eneolithic. These include silty clays selection traditions, the introduction of artificial additives into the molding composition: crushed shell, bird fluff and sand.

Keywords: Lower Don; Rakushechny Yar settlement; Neolithic; Eneolithic; ceramics; historical and cultural approach to study of ceramics; binocular microscopy; trasology; experiment; pottery technology; cultural traditions; comparative analysis of Eneolithic and Neolithic pottery traditions.

УДК $902 / 904$

DOI 10.24411/2309-4370-2019-12206

Статья поступила в редакцию 02.02.2019

\title{
НАЧАЛО «ЭПОХИ РАННЕГО МЕТАЛЛА» НА ТЕРРИТОРИИ КАРЕЛИИ: МАТЕРИАЛЫ И ИССЛЕДОВАНИЯ
}

\section{(C) 2019}

Васильева Татьяна Анатольевна, кандидат исторических наук, научный сотрудник сектора археологии Институт языка, литературы и истории Карельского научного иеетта РАН

(2. Петрозаводск, Российская Федерация)

\begin{abstract}
Аннотащия. В работе представлены результаты археологического изучения переходного этапа от эпохи камня к «эпохе раннего металла». Этот период на территории Карелии характеризуется культурами с гребенчато-ямочной и ромбо-ямочной керамикой, вопросы развития которых остаются нерешенными. Основная задача исследования заключается в представлении материалов и степени изученности культур переходного этапа от неолита к энеолиту. Особое внимание уделено памятникам с ромбо-ямочной керамикой, в материалах которых присутствуют первые признаки знакомства населения с металлом. С увеличением корпуса источников, их анализом происходит переосмысление основных положений в развитии культурных процессов. Керамика является первым искусственным материалом, созданным человеком. Орнаментация керамики служит культурно-определяющим маркером при изучении древних культур. При анализе керамических материалов эталонных памятников замечено, что по морфо-типологическим признакам глиняная посуда, декорированная оригинальным элементом в виде ромбовидных и ромбических ямок, близка к керамике с ямочногребенчатой системой орнаментации. В статье автор обосновывает свое представление об отнесении памятников с ромбо-ямочной керамикой к переходному этапу от неолита к энеолиту. В центре внимания исследователя - особенности развития древнего гончарства в IV - начале III тыс. до н.э.

Ключевые слова: эпоха раннего металла; охотничье-рыболоведческие хозяйства; памятники с гребенчатоямочной и ромбо-ямочной керамикой; глиняная посуда; орнаментация; древнее гончарство; медные изделия; переходный этап от неолита к энеолиту; IV-III тыс. до н.э.; культурная преемственность; территория Карелии.
\end{abstract}

На территории Карелии период освоения металла связан с переходным этапом от эпохи камня к «эпохе раннего металла», который представлен культурами с гребенчато-ямочной и ромбо-ямочной керамикой, период их существования относится к IV - началу III тыс. до н.э. Вопросы происхождения и развития культур остаются дискуссионными. Одни исследователи полагают, что они не преемственны в культурном плане друг другу [1, с. 137; 2, с. 155-156], другие отмечают их связь $[3$, с. $47 ; 4$, с. 90-92; 5, с. 42]. Первые медные изделия выявлены Н.Н. Гуриной на памятниках с ромбо-ямочной керамикой (Деревянное I, Войнаволок IX и Оровнаволок II), что позволило выделить главным признаком энеолита в лесной зоне знакомство населения с металлом, второстепенным изменения в керамике и формах каменного инвентаря. К «эпохе раннего металла» ею отнесены памятники энеолита, бронзы и раннего железа [6, с. $77-$ $142 ; 7$, с. 81-112].

К началу 1950-х гг. сформировалось понимание «эпохи раннего металла» как границы между неолиСамарский научный вестник. 2019. Т. 8, № 2 (27) том и бронзой среди исследователей Севера. А.Я. Брюсов к эпохе бронзы относил памятники, которые свидетельствуют не только об умении изготавливать металлические орудия, но имеют хронологическую привязку и создают типологические ряды. Отсутствие либо единичность последних, либо наличие привозных металлических изделий является показателями неолитического времени [8, с. 6-7]. М.Е. Фосс в целом была сторонницей данного положения, за исключением тезиса о наличии типологических рядов [7, с. 82].

В.А. Городцов с эпохой раннего металла - «палеометалла» - связывал памятники с единичными изделиями или шлаками. Н.Н. Гурина, опираясь на данное высказывание, выделяла специфические условия исторического развития на северных территориях. Основным признаком, указывающим на соотнесение памятников с эпохой раннего металла, по ее мнению, являлось знакомство населения с изготовлением металлических изделий, а также наличие существенных изменений в древнем гончарстве и каменной индустрии [7, с. 83]. 